\title{
UNA CUESTIÓN DE ETIQUETA
}

\author{
PETER MASON \\ ROMA $^{1}$
}

RESUMEN: El texto se ocupa de analizar cómo las distintas etiquetas aplicadas a un cráneo sobremodelado melanesio en un museo portugués arroja luz sobre la pluralidad de los contextos en los que este objeto se puede insertar. También plantea preguntas acerca de la política y la poética de la exhibición de los artefactos no europeos en los museos europeos.

Palabras clave: Melanesia, Portugal, análisis del discurso, exhibición museística, contextualización, autenticación.

Авsтract: Analysis of the various labels applied to a Melanesian overmodelled skull in a Portuguese museum throws light on the plurality of contexts into which this object can be and has been inserted. It also raises questions about the politics and poetics of the display of non-European artefacts in European museums.

KEYwords: Melanesia, Portugal, discourse analysis, museum display, contextualization, authentication.

\section{Objetos exóticos e historia no colonial}

La expansión portuguesa llevó consigo transformaciones profundas en el conocimiento del espacio geográfico, náutico y topográfico, no sólo en la época de las misiones científicas del siglo $\mathrm{XVIII}^{2}$, sino también en los años anteriores, durante los cuales el viajar todavía no había sufrido la institucionalización

\footnotetext{
1 monti55@fastwebnet.it

2 W.J. Simon (1983), Scientific Expeditions in the Portuguese Overseas Territories (1783-1808) and the Role of Lisbon in the Intellectual-Scientific Community of the Late Eighteenth Century, Lisboa, 1983. Para una síntesis de la historiografía portuguesa de las expediciones, véase D. Ramada Curto, (2007: 37-43), «Portuguese Navigations. The Pitfalls of National Histories» en J. A. Levenson (ed.), Encompassing the Globe. Portugal and the World in the $16^{\text {th }}$ and $17^{\text {th }}$ Centuries, cat. muestra, Smithsonian Institution, Washington.
} 
científica que iba a ocurrir más tarde ${ }^{3}$. Al mismo tiempo, esta expansión de los horizontes europeos nos deja frente a un tipo de espacio diferente, al espacio como forma de saber:

«[...] organisation de lieux mnémoniques et sapientiaux, structure d'énonciation et de discours, depuis les arts de la mémoire en vogue chez les adeptes de l'éloquence judiciaire ou sacrée jusqu'aux lieux successifs et disjoints de la chronique rabelaisienne; à l'archipel infiniment morcelé des Isolarii ou Insulaires égéens et océaniques; aux feuilles d'atlas qui contiennent en réserve les leçons de l'Écriture Sainte et servent de support aux «meditations cosmographiques» de Gérard Mercator»(Lestringant, 1993: 8)

Junto al espacio en dos dimensiones de los textos contemplados por Lestringant, podemos añadir el espacio en tres dimensiones ocupado por objetos que transitaron las rutas de la expansión europea en dirección contraria; objetos no europeos que fueron llevados a Europa juntos con los relatos correspondientes. Por ejemplo, el cosmógrafo francés André Thevet, que regresó a Europa después de una estadía de diez semanas en el Brasil con suficiente información para hacerse una autoridad sobre las Américas mediante la publicación de su Les Singularitez de la France Antarctique, Autrement nommée Amerique (Paris, 1557), llevó también consigo mantas y flechas patagonas, plumajes multicolores de pájaros, un tucán y una clava para aumentar las colecciones del rey de Francia (Mason: 2002).

Con el surgimiento del museo como institución pública, los objetos traídos de culturas no europeas fueron adquiridos en una escala cada vez mayor por los museos de etnología durante los siglos XIX y XX. La investigación de estos objetos aislados puede proporcionar información sobre los contextos culturales de los cuales fueron sacados; de la investigación de su colocación en el marco de las colecciones europeas, se puede derivar información sobre las categorías y estructuras intelectuales europeas de esa época. En suma, la investigación del rol de los objetos no europeos en un país europeo, como es el caso de Portugal, podría resultar ser una contribución valiosa a la historia portuguesa.

En un breve examen histórico del traslado de objetos no europeos a los museos europeos, George Stocking (1985: 4-5), indica cómo los procesos históricos que condujeron a la colección de tales objetos, se relacionan tanto con

3 Véase, p.ej., J. Borges de MACEdo (1991: 139-168), «Observação. cultura científica e descobrimentos», Portugaliae Historica, 2a serie, vol. 1. 
las fuerzas del desarrollo económico y del nacionalismo que trasformaron la Europa en el transcurso del siglo XIX, como con las del dominio imperial. Esta inscripción de tales objetos de tres dimensiones dentro de específicos procesos históricos constituye su cuarta dimensión, la de la historia.

Stocking, sin embargo, añade otras dimensiones a la discusión. Su quinta dimensión es la del poder y expropiación:

«Since the objects thrown in the way of observers in museums were once those of others, there are relations implicit in the constitution of a museum which may be defined as relations of «power»: the expropriation (not only in an abstract etymological sense, but sometimes in the dirty sense of theft or pillage) of objects from actors in a particular space, time, and meaning and their appropriation (or making one's own) by observers in another» (ibid. 5).

Finalmente, tenemos que darnos cuenta de dos dimensiones más, las cuales podemos clasificar bajo el rótulo del valor: la dimensión de la riqueza — los modos en que los objetos de cultura material se involucran en procesos económicos de adquisición e intercambio de riqueza-y la de su atracción estética, relacionada esta con un sinnúmero de consecuencias de la presencia del «arte primitivo en sitios civilizados» (Price, 1989).

En los comentarios siguientes, presentaré diversas lecturas de un artefacto etnográfico que formó parte de una colección portuguesa a principios del siglo XX. Trabajando como un arqueólogo, voy desenterrando algunos de los estratos que constituyen este particular espacio portugués: espacio epistemológico, en el cual el discurso sobre los objetos se vuelve un discurso sobre seres humanos, o sea sobre los portugueses que se encargaron de la tarea de clasificar estos objetos. Sería difícil considerar el objeto del cual se trata aquí — un cráneo sobremodelado de Nueva Guinea - como relevante de la historia colonial portuguesa (Nueva Guinea no fue nunca una colonia portuguesa). De todas maneras, aunque pueda parecer paradójico, veremos que una reflexión sobre este cráneo —un «típico» objeto etnográfico- puede contribuir a la historia portuguesa no colonial. Además, trataré de demostrar cómo los relatos relacionados con un objeto pueden narrar y producir un cierto tipo de historia, y cómo por ello, es que uno puede someter estos relatos a los análisis que se aplican más comúnmente a los textos escritos. Al mismo tiempo, el hecho de haber escogido un objeto plástico como nuestro punto de partida, tiene la ventaja de asegurarnos de que nunca podremos agotar su potencial. Francisco Gallardo (1995: 32) ha escrito 
que la intensidad de las diferencias vividas por el antropólogo alcanza su mayor grado de condensación en la escritura, en la textualidad. Por el acto de salir del interior del texto, sabemos que ningún relato —incluso este relato- será nunca totalmente adecuado al objeto. En este sentido, la materialidad misma del objeto, constituye una resistencia al orden disciplinario del discurso.

\section{Lecturas: la lección de etiqueta}

Al contemplar la condición de la antropología portuguesa en el año 1991, Jean-Yves Durand describió la rápida emergencia de la antropología física debida a la institucionalidad, primero en Coimbra en 1885, y después en Oporto en 1911. A finales de la década del 20, existía no sólo un Instituto de Antropología, sino también un museo del mismo instituto, que disponía de:

«colecçôes osteológicas, somatológicas, de algumas peças de Pré-História e de Arqueologia, finalmente, de um pequeno acervo etnográfico portugês, sobressaindo 105 rocas, 98 fusos, 32 candeias e 22 lampióes doados por um particular», Vasco Nogueira de Oliveira (Bouquet y Freitas, 1988: 124).

La Escuela de Oporto, en su devenir, fue dominada por un determinismo biológico, hecho que la predisponía a colaborar, al menos ideológicamente, con las políticas de la dictadura militar, no sólo en Portugal sino también, aunque menos enérgicamente, en las colonias portuguesas en África. Creían que la fisonomía formaba parte de un paradigma evolutivo en el que "el otro" —en términos raciales o clásicos- fue relegado a una posición subordinada con respecto al ojo hegemónico.

Aunque sí se prestaba atención a características como la postura corporal, se le daba prioridad al cráneo como repositorio de tipos raciales. La craneometría, sobre todo en combinación con el emergente fenómeno del retrato fotográfico ${ }^{4}$, iba tomando precedencia a la osteometría. No sorprende, entonces, que entre un número de objetos melanesios que llegaron a Portugal en el año 1927 y que

${ }^{4}$ Ver R. Poignant (1992), «Surveying the Field of View: The Making of the RAI Photographic Collection», en: E. Edwards (ed.), Anthropology and Photography 1860-1920, New Haven y Londres, pp. 42-73, y F. Spencer (1992), "Some Notes on the Attempt to Apply Photography to Anthropometry during the Second Half of the Nineteenth Century», en ibid., pp. 99-107. 
ahora pertenecen a la Universidad de Oporto, se encuentre un cráneo (figura 1). Es uno más entre 100 objetos melanesios que fueron donados a Portugal en ese año por los museos alemanes agrupados en el Staatlichen Museen Preussischer Kulturbesitz como recompensa de los artefactos asirios que habían sido confiscados en el ańo 1916 al declararse la guerra a Portugal ${ }^{5}$. Se nota que este cráneo es uno de los pocos objetos osteológicos en la colección; los demás objetos son faldas, decoración corporal, vasijas y utensilios, hachas, etcétera.

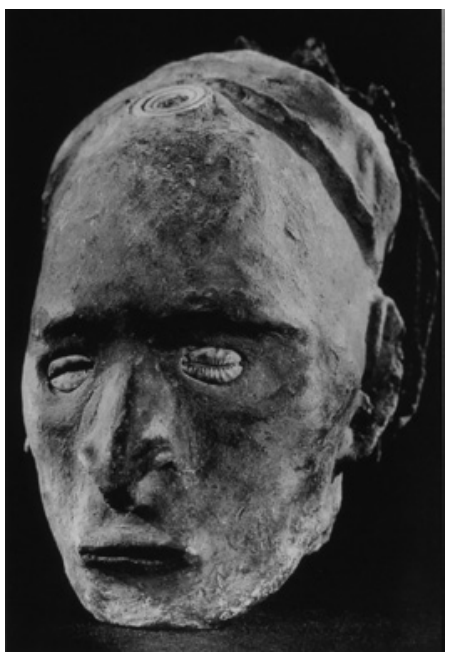

Figura 1

Aparte de estas consideraciones craneométricas, no olvidemos que el cráneo jugó un papel importante en la imaginación popular de la cultura melanesia, la cual se representaba como una sociedad de cazadores caníbales. Es un hecho singular que los europeos en Melanesia parecen haber tenido al menos tanto interés por la caza de cráneos: durante su primera misión en Melanesia, Richard Thurnwald ${ }^{6}$ recogió 200 cráneos, menos que los 800 cráneos recogidos por Otto Schlaginhaufen a favor de la Deutsche Marine-Expedition en los años 1907-1909. La expedición Sepik (1912-1913), también llamada la KaiserinAugusta-Fluss-Expedition, dio lugar a una colección de 300 cráneos y tres esqueletos casi enteros (Bouquet y Freitas, 1988: 34-44).

5 Museu de Antropologia da Universidade do Porto (84.01.071). Sobre las vicisitudes de los objetos melanesios en la colección de Oporto véase la reconstrucción detallada en Bouquet y Freitas Branco (1988).

${ }^{6}$ El funcionalismo histórico de Thurnwald dejó su huella sobre los estudios antropológicos en Munich, donde Jorge Dias, nombrado director del Centro de Estudios Etnológicos Peninsulares en 1945, obtuvo su doctorado. 
Ambas connotaciones del cráneo — como recuerdo de la práctica "primitiva» de la caza de cráneos, y como objeto de valor capital en los estudios craneométricos- se evocan en la descripción del objeto que le acompañaba cuando pasó dentro la colección de Oporto como el ítem número 84.01.071: «Crânio melanésio embelezado com conchas de mariscos, raça negróide do Pacífico, Nova Guiné» (Bouquet y Freitas, 1988: 56) ${ }^{7}$. Como cráneo, se ajustaba bien a las implicaciones de la etiqueta que se aplicó a una clava: el término francés «cassetête» (literalmente «rompecabezas») tenía una resonancia más grande, evocativa de la caza caníbal, que la palabra portuguesa «clava».

Efectivamente, ni "crânio" ni "cabeça mumificada» —otra etiqueta que se pegó al objeto- le cuadra a su naturaleza. No es meramente un cráneo, porque ha sido sobremodelado, un proceso en el cual los cráneos de los enemigos matados fueron sobremodelados con arcilla, cocidos, y pintados; en las cuencas les pusieron conchas de mejillones. Esta técnica no tiene nada que ver con la momificación, proceso en que el cráneo se seca. Mientras que «crânio» y "cabeça» recuerdan el hecho de que el cráneo probablemente pertenecía a un enemigo, evocando así la ferocidad atribuida a los melanesios, el segundo término de cada par («embelezado» $\mathrm{y}$ "mumificada») enfatiza la posesión de una capacidad cultural en las técnicas de preservar y modelar. La misma oposición caracteriza el término alemán para tales cráneos: aunque ya no hay ninguna etiqueta alemana para este cráneo sobremodelado, la lista en Berlín tiene referencia a un Zierschädel, o sea cráneo decorado (ibíd.: 122), lo que implica la misma oposición entre una ferocidad natural y la obra de cultura. Y, ya que uno de los directores del Museo Etnológico en Berlín, Felix von Luschan, consideraba el descubrimiento etnológico de la región sepik de la Nueva Guinea como el acontecimiento de mayor alcance científico después de la revelación de los tesoros de Benín (ibíd.: 60), es interesante notar la misma oscilación entre el salvajismo y el reconocimiento de capacidades culturales en el caso de la recepción europea de los tesoros de Benín. Así que dos mazas de Benín, descritas en una publicación británica en el año 1897 como «ídolos marfileńos llevados por el verdugo», llegaron a ser «dos mazas marfileñas de Benín» dos años más tarde bajo el impacto de la muestra de más de 300 placas de bronce de Benín (Coombes, 1994: 27).

${ }^{7}$ Existen tres tipos de evidencia documental sobre estos objetos: las etiquetas alemanas pegadas a 48 de ellos, aparentemente escritas antes de la llegada de los objetos en los museos de Berlín; las etiquetas portuguesas añadidas en los ańos 20 y remplazadas antes del año 1940; y las descripciones en el catálogo hechas por el Museo de Antropología antes del año 1984, año en que la colección fue trasladada a Lisboa para ser restaurada (BouQuet y Freitas Branco, 1988: 25-26). 
La misma incertidumbre con respecto a la clasificación de una sociedad "primitiva» caracteriza los términos geográficos utilizados para indicar el lugar de origen de los objetos. «Mumificada» evoca histórico-geográficamente, civilizaciones ancianas que practicaban la momificación; aunque la técnica era también conocida por las sociedades antiguas de América del Sur y por otras culturas, en Europa después de Heródoto el término tenía una resonancia sobre todo faraónica ${ }^{9}$. Subyacente al paralelismo implícito entre las sociedades melanesias contemporáneas y las del Viejo Mundo existe una fusión entre lo "primitivo» y lo «arcaico»: lo que es remoto (y culturalmente inferior, es decir, primitivo) en el espacio se asimila a lo que es remoto (y culturalmente inferior, es decir, arcaico) en el tiempo ${ }^{10}$. En cuanto a los términos geográficos mismos, «melanesio» y «Pacífico» son bastante equívocos y apenas refieren a entidades geográficas específicas. Además, la inserción de la palabra «Pacífico» dentro de la designación «raça negroide do Pacífico» implica que la distinción racial tiene primacía sobre la referencia geográfica, según la conocida asunción del siglo XIX de que exista una relación íntima entre raza y cultura. Efectivamente, el mundo evocado por esta etiqueta no es un mundo topográfico, sino el mundo autoritario de los manuales de la antropología física que estaban de moda en Oporto.

Quizás valga la pena relacionar este desinterés por la precisión geográfica con la historia más temprana del contacto portugués con los objetos etnográficos. Por ejemplo, la documentación que acompañaba a los especímenes recolectados durante el Viagem Philosóphica a la Amazônia por Alexandre Rodrigues Ferreira entre 1783 y 1792, revela un similar grado de imprecisión etnográfica cuando se trata de la descripción de artefactos como la ropa, las herramientas, los ornamentos corporales, los instrumentos de música y las armas; los objetos son clasificados solamente en términos funcionales, sin demasiado respeto por los determinantes

8 Por ejemplo, había hombres cavernícolas que momificaban a su muertos en el archipiélago canario a la fecha de la llegada de los europeos; véase A. Tejera y R. González (1997), Las culturas aborigenes canarias, Santa Cruz de Tenerife.

9 Sobre el interés por la momificación egipcia en las colecciones de curiosidades de los siglos XVI y XVII, véase A. Schanapper (1998), Le géant, la licorne, la tulipe. Collections françaises au XVIIe siècle, París, pp. 95-97. El artista y coleccionista Peter-Paul Rubens tenía una momia egipcia, de la cual mandó un dibujo al anticuario francés Peiresc en 1625; véase K.L. Belkin y F. H. Healy (eds.) (2004), A House of Art. Rubens as Collector, cat. muestra, Rubenshuis, Amberes, 2004.

10 Sobre la relación entre el primitivismo y el arcaismo véase la discusión en C. Rhodes, Primitivism and Modern Art, Londres, 1994. 
específicamente étnicos o geográficos ${ }^{11}$. No obstante, la ausencia de la especifidad geográfica era una característica de las colecciones de curiosidades de la época del renacimiento, y caracteriza también las colecciones más recientes.

La misma ausencia de precisión geográfica caracteriza el rótulo que pertenece a otro artefacto de la misma colección portuguesa. Un puñal decorado de hueso, no. 84.01.006, lleva la etiqueta «Punhal, Baía de Dalmann, Arq. Palmer O. Antártico» (Bouquet y Freitas: 50). La referencia al Antártico introduce los nombres exóticos para comunicar un aire poco precisado que evoca lo remoto en lugar de una localidad bien definida.

Para regresar a nuestro cráneo sobremodelado, podemos interpretar la inscripción de los objetos etnográficos dentro de específicos procesos históricos literalmente como un proceso de inscripción: son las varias inscripciones en las etiquetas pertenecientes al objeto, las que señalan específicos procesos históricos en Melanesia, Portugal y Alemania en los siglos XIX y XX.

De hecho, es la misma inscripción de los objetos etnográficos dentro de los procesos históricos y económicos específicos, la que se esconde, por su separación de un contexto histórico-geográfico más preciso. Así, la atención se desvía de un factor muy material —el hecho que los cráneos decorados (y no decorados) se usaban en la Nueva Guinea en los intercambios con los alemanes-. Y esto, después de todo, explica porqué fueron incluidos en el cargamento alemán que finalmente llegó a Portugal.

La separación de la que aquí se trata, es el acto físico de arrancar, que posibilita la fragmentación (Kirshenblatt-Gimblett, 1991: 388). Y es esta separación, la que facilita el aprecio estético de tales obras, la implicación compleja de valor, riqueza y estética a la que se refiere Stocking. Señalamos el caso de los colmillos y las placas de bronce que arrancaron los británicos a la ciudad de Benín durante la expedición punitiva del año 1897. Estos objetos impresionaron fuertemente al público británico, puesto que el alto grado de elaboración técnica facilitaba su incorporación dentro de los marcos estéticos establecidos (Goldwater, 1986: 88). De hecho, los

${ }_{11}$ M. L. R. de Areia y M A. P. Miranda (1995), "A Philosophical Journey to the Amazon, 1783-92. The story of the gathering and dispersal of a collection", Journal of the History of Collections 7 (1), pp.59-71; cf. J. Saporiti Machado y M. Telles Antunes (2014), «Aniceto Rapozo’s cabinet at the Lisbon Academy of Sciences. A window into Brazilian eighteenth-century timber resources", Journal of the History of Collections 26 (1), pp. 21-33, aquí p. 22. 
escritores que no podían creer que un arte tan fino se originara en África, señalaron de manera hipotética que las placas de bronce tuvieran eslabones con Egipto o Portugal (Coombes, 1994). La apreciación estética de los artefactos etnográficos, presupone entonces un acto de arranque de su contexto local cultural y una inserción dentro de un sistema de valores distinto: en el presente caso, europeo.

El hecho de que los artefactos exóticos tengan un contexto no sólo en las culturas de donde se sacaron, sino también dentro de las culturas huéspedes, ha sido enfatizado por Jane Peirson Jones en su discusión sobre la presentación de artefactos etnográficos en la Gallery 33, Birmingham, Inglaterra:

«The artifact ceases to be a relic of an exotic past, or a work of art, or simply a piece of loot. Instead it becomes symbolic of complex colonial and postcolonial relationships, and can inform our understanding of the presentday world» (Jones, 1992: 235).

Sin embargo, el objeto no deja de ser una reliquia de un pasado exótico, o una obra artística. Es todas estas cosas, y acaso más. Pues no podemos aceptar el arranque como acto definitivo. La separación del objeto de su contexto anterior nos ayuda a olvidarnos de que el cráneo pertenecía a un ser humano. Mostrado de una manera que sería inaceptable si se aplicase a un pariente del conservador del museo, por ejemplo, el cráneo se puede mostrar justamente a causa de su distancia, en el tiempo y en el espacio, de la nueva modalidad de muestra dentro de un museo. A través de la noción del proceso de sobremodelar, la idea de un artefacto embellecido reemplaza la idea de un resto de una persona que ha vivido en el pasado. En este sentido, la muestra de este (o cualquiera) cráneo en el contexto de un museo, pertenece a la tradición larguísima, europea y no europea, de exhibir a los seres humanos, vivos o muertos ${ }^{12}$.

Al iluminar el proceso de separación, tenemos también que considerar la manera cómo el cráneo ha sido presentado, no sólo a través de sus etiquetas alemanas o portuguesas, sino también en términos de su adquisición por medio de una etiqueta más en los ańos 80: ahora se nombra el ítem 109, crânio sobremodelado, Sepik, $27 \mathrm{~cm}(\mathrm{~h}), 15-17 \mathrm{~cm}(\mathrm{w})$ en el catálogo bellísimo compilado por Bouquet y Freitas Branco (1988: 187). Pues también podemos considerar

12 Para ilustrar esto véase C. BÁez y P. Mason (2010), Zoológicos Humanos. Fotografías de fueguinos y mapuche en el Jardin d'Acclimatation de París, siglo XIX, Pehuén Editores, Santiago de Chile, 2006, segunda edición 2010. 
el lema en el catálogo como una etiqueta; no importa si corresponde a un texto legible cerca del objeto mostrado o no ${ }^{13}$. La inclusión de las dimensiones del cráneo, información que no necesita quien lo está mirando, introduce el tema de la ausencia ${ }^{14}$. Sólo pueden interesar al observador ausente que no puede mirar el cráneo personalmente, condenado (como nosotros) a verlo a través de una representación. En otras palabras, la precisión física de las dimensiones «27 cm (h), 15-17 cm (w)» tiene sentido sólo cuando esta dimensión física está ausente. Como señala Baxandall: «The nearest thing the label offers to a description is the numerical statement of the object's dimensions — something of which the viewer, who can see the object, is unlikely to make very active use» (Baxandall, 1991: 38).

La etiqueta, entonces, llama la atención a la naturaleza representacional de lo que se muestra (en este caso la hoja impresa) como no auténtica. Como semioforo - para usar el término introducido por Pomian para distinguir entre cosas en sí mismas y artefactos que se coleccionan como soportes de significación- el cráneo sobremodelado trasciende la esfera de experiencia sensorial inmediata, por establecer la comunicación entre lo visible y lo invisible (Pomian, 1987: 42). En el caso presente, lo invisible tiene que ver no sólo con el mundo Sepik, sino también con el mundo de los muertos. Por eso, el cráneo sobremodelado elabora y articula la ausencia de esos mundos.

Segundo, como la etiqueta portuguesa «raça negróide do Pacífico, Nova Guiné», incluye las dimensiones físicas, evoca al mundo de la precisión científica, y con ello a la autoridad académica de una disciplina que se basa en una precisión de este tipo. Notemos, además, que esta resonancia particular se presta para todo el contenido del rótulo: ya que las dimensiones físicas son incontrovertibles, toda la información contenida por la etiqueta, tiene que ser incuestionable.

Tercero, la inclusión del nombre Sepik, funciona sobre distintos registros. Significa un abandono de las reverberaciones egipcias o sudamericanas de «cabeça mumificada», de la impresión geográfica de "melanésio» y de la geográficamente más imprecisa «raça». Sin embargo, el mismo término «Sepik» sufre también una

13 Sobre este uso del término «etiqueta» véase M. Baxandall (1992: 33-41, aquí 37), «Exhibiting Intention: Some Preconditions of the Visual Display of Culturally Purposeful Objects», en: I. Karp y S. D. Lavine (eds), Exhibiting Cultures. The Poetics and Politics of Museum Display, Washington y Londres. Puesto que no he visto la muestra en Portugal, tengo que eludir la relación entre la muestra misma y su huella en el catálogo.

14 Sobre los problemas técnicos involucrados en la reproducción en dos dimensiones de cráneos para proporcionar información científica «mensurable» véase Spencer (1992). 
falta de precisión. Históricamente, evita cualquier referencia a la existencia temporal del cráneo: como artefacto sin fecha, evocando la existencia humana en su sentido más amplio (como nos recuerda el motivo momento mori, una de las características de la humanidad es el hecho que todos tenemos un cráneo), el cráneo pertenece a la misma temporalidad que el llamado presente etnográfico. Geográficamente, el término «Sepik» limita el enfoque del término «Melanesio» al territorio «Sepik». Sin embargo, en un estudio del arte «Sepik», Nicholas Thomas (1995) ha señalado que el enfoque del término «Sepik» queda mal definido en vista de las diferencias dentro de las categorías del arte Sepik (Lower Sepik, Middle Sepik, etc.).

A nivel estético, el hecho de que ocho «cráneos sobremodelados Sepik» más se reproduzcan en la misma hoja del catálogo como ejemplos de disposiciones gráficas indica cómo los autores quieren que se lea este cráneo: como ejemplo de la decoración corporal, practicada con un grado de sutileza que falta en los ejemplos de Nueva Irlanda.

Como etiqueta, entonces, la descripción produce un efecto de (re)articulación con autoridad, dicta al observador cómo mirar el objeto mostrado. En el acto de aplicar una etiqueta a un artefacto, se le atribuye una significación que es conveniente dentro de un contexto y menos conveniente dentro de otro. Esto es inevitable. Entonces, mientras que es de una importancia trascendente entender el contexto, las cuestiones de lo que se puede considerar como contexto y de cómo se relaciona con los objetos de arte, no son siempre sencillas. Objetos arrancados, comprados o robados de un lugar y mostrados en otro lugar, participan en un proceso de recontextualización creativa. No hay ninguna norma o convención para evaluar la conformidad de etiquetas distintas a la "verdad». O siempre hay un contexto en que una etiqueta se encaja, pero la retórica y la política puesta en marcha varía de una etiqueta a otra. Pues cualquiera etiqueta, tal como cualquier presentación en un museo, es conforme al hecho de que:

"What it [the public] sees is not material that «speaks for itself» but material filtered through the tastes, interests, politics, and state of knowledge of particular presenters at a particular moment in time. [...] It could hardly be otherwise.» (Vogel, 1991: 201).

Por supuesto, mis observaciones están necesariamente sujetas a las mismas condiciones. Todas las etiquetas que cito aquí son sólo eso, fragmentos sacados de una pluralidad de discursos que se entrecruzan en la figura del cráneo sobremodelado. De hecho en este sentido la reproducción fotográfica del cráneo en 
estas hojas, arrancada de todo contexto (Melanesia, las relaciones comerciales entre Alemania y Nueva Guinea, la historia de la etnografía portuguesa, etc.), no es más que otra etapa en una serie potencialmente infinita de citas e injertos.

Obviamente, estas observaciones se refieren a preocupaciones que son más europeas que melanesias. Efectivamente, algunos antropólogos han señalado la relativa ausencia de explicaciones verbales de los artefactos por los melanesios mismos, aunque O'Hanlon (1992) nota la importancia de consideraciones verbales de los artefactos melanesios, en lugar de explicaciones. Investigando la discrepancia entre texto e imagen, ya nos hemos colocado dentro de un marco de preocupaciones europeas y no melanesias. Además, la tendencia de enfocar las cuestiones de cómo y por quién los objetos exóticos fueron recogidos dentro de un contexto colonial, y en la necesidad de explicitar estas historias dentro de la preocupaciones museográficas, ha sido criticada por algunos como una preocupación sobre todo europea (Jones, 1992: 237). Acaso podríamos considerar la discrepancia entre texto e imagen como síntoma de resistencia del exótico a su apropiación. De todas maneras, las etiquetas consideradas aquí no constituyen una identidad, son intervenciones en una lucha representacional sobre la reinvención y rearticulación de identidades distintas.

Este rol activo de las etiquetas en la reapropiación de objetos y en la producción de nuevas significaciones ha sido discutido por James Clifford, en relación a algunas muestras de «arte primitivo» en los Estados Unidos de los años $80^{15}$. Clifford formula su intención general así:

«To displace any transcendent regime of authenticity, to argue that all authoritative collections, whether made in the name of art or science, are historically contingent and subject to local reappropriation» (Clifford, 1988: 10).

También las etiquetas que estamos considerando operan dentro de regímenes de autenticidad, por ejemplo, la manera en que algunas etiquetas ocultan el hecho de que el cráneo existe en un tiempo histórico, asimilando así su existencia a la eternidad del presente etnográfico, lo que contribuye, en definitiva, a reforzar la autoría de la voz que lo describe, ya que el presente es una señal que significa que un discurso pertenece al lenguaje del observador (Fabian, 1983: 86). Efectivamente, sería mejor hablar de regímenes de autenticación, en lugar de regímenes de autenticidad, puesto que en la polémica implícita entre las mismas,

15 Ver J. Clifford (1988: 189-214) y cf. R. y S. Price (1995: 97-109). 
las etiquetas se involucran en un proceso que se centra en la definición misma de lo auténtico. Cada etiqueta, como definición persuasiva, presenta un ensayo de interpretar este artefacto específico en función de su imagen particular de la alteridad. Cada etiqueta es un ensayo creativo de producir significación.

\section{Hacia una pluralidad de historias}

Como hemos visto, la inscripción de objetos etnográficos dentro de procesos históricos específicos puede interpretarse literalmente como acto de inscripción. A su vez, el carácter de este proceso de inscripción nos dice algo sobre la naturaleza del espacio histórico con que empezamos: el espacio como forma de saber.

Primero, este espacio es una entidad heterogénea. No hay ningún lugar preformado en que se pueda insertar el cráneo. Por el contrario, se encaja dentro de un número de contextos distintos, de los cuales se traslapa o entrecruza, pero que pertenecen a temporalidades distintas. Algunos de los contextos señalados arriba — por ejemplo, la cuestión ética de la muestra de restos humanos- son seculares. Otros - como el sistema de relaciones de poder dentro de los cuales el cráneo se trasladó de Nueva Guinea a Portugal— están estrechamente relacionados con tiempos y lugares muy específicos.

Segundo, ninguno de dichos contextos tiene prioridad. En esta etapa de la investigación, priorizar cualquier contexto particular, sería una opción a priori injustificada. Quizás esta posición podría parecer, a ojos de algunos, como una permisividad relativa. Thomas, por ejemplo, rechaza la descontextualización estética de unas muestras de los tallados, tejidos y obras de plumas de los maoríes con el argumento de que excluyen los contextos no tradicionales de producción. El mismo opta por lo que llama "el valor trascendental de la relevancia política» (1994: 19-20). Pero si uno acepta la recontextualización permanente de los objetos del discurso, dependiente no sólo de parámetros políticos sino también de las perspectivas estéticas, religiosas, culturales y otras, se hace difícil ver cómo uno de estos niveles podría asumir prioridad como valor trascendental. Igualmente que no existe ninguna identidad original en que se fundamente la recontextualización (Thomas, 1991: 187), tampoco hay ninguna recontextualización trascendental en que se fundamente el análisis. Lo que se contempla en el análisis presente, por el contrario, es el proporcionar una lógica, por intermedio de la cual se puede decidir cuál es el contexto más urgente en que se encaja un caso particular en base al caso mismo ${ }^{16}$.

16 Para una argumentación más detenida de esta posición véase Mason, 1995. 
El sugerir que reflexiones sobre un cráneo sobremodelado podrían contribuir a la historia portuguesa no significa que estoy demostrando la existencia de una laguna que ahora está rellenándose; ni estoy defendiendo una concepción triunfalista de la historia como compendio siempre creciente de información enciclopédica. En cambio, espero que el caso de este cráneo haya señalado la existencia de una pluralidad de historias, la heterogeneidad de las cuales imposibilita fundamentalmente la obtención de cualquier síntesis definitiva. Llegado a este punto, entonces, el rumbo de toda la argumentación se pone al revés: empezamos por la incorporación de un membrum disiectum dentro de la historia portuguesa, y terminamos por fragmentar la historia en una pluralidad de membra disiecta.

\section{Agradecimientos}

Sobre todo a Marisol Palma y Eduardo Llanos por su ayuda material y espiritual en la redacción del texto. A Carol Sinclaire y Francisco Gallardo y los demás del Museo Chileno de Arte Precolombino, Santiago de Chile, donde he tenido el privilegio de presentar una versión preliminar de este artículo. Y a Mary Bouquet y Florike Egmond por sus comentarios siempre críticos.

\section{Bibliografía}

Baez C. y Mason, P. (2006). Zoológicos Humanos. Fotografias de fueguinos y mapuches en el Jardin d'Acclimatation de París, siglo XIX. Santiago de Chile: Pehuén Editores.

Baxandall, M. (1991). «Exhibiting Intention: Some Preconditions of the Visual Display of Culturally Purposeful Objects», en: I. Karp y S. D. Lavine (eds.), Exhibiting Cultures. The Poetics and Politics of Museum Display. Washington y Londres: Smithsonian Institution, pp. 33-41.

Belkin, K. L. y Healy, F. (eds). (2004). A House of Art. Rubens as Collector, Amberes, cat. muestra, Rubenshuis, pp. 296-297.

Borges de Macedo, J. (1991). «Observação, cultura científica e descobrimentos", Portugaliae Historica, 2.a série, vol. 1, pp. 139-168.

Bouguet M. R. y Freitas, J. (1988). Artefactos Melanésios. Reflexóes pós-modernistas / Melanesian Artefacts. Postmodernist reflections, Lisboa: Museo de Etnologia.

Clifford, J. (1997). «Four Northwest Coast Museums: Travel Reflections», en: I. Karp y S. D. Lavine (eds), Exhibiting Cultures. The Poetics and Politics of Museum Display, Washington y Londres: Smithsonian Institution, pp. 212-254. 
- (1988). The Predicament of Culture. Cambridge, Mass. y Londres: Harvard University Press, 1988, pp. 189-214.

Coombes, A. E. (1994). Reinventing Africa. Museums, Material Culture and Popular Imagination, New Haven y Londres: Yale University Press.

De Areia, M. L. R. y Miranda, M. A. P. (1995). «A Philosophical Journey to the Amazon, 1783-92. The story of the gathering and dispersal of a collection», Journal of the History of Collections 7 (1), pp. 59-71.

Durand, J. Y. (1991). "Où la terre s'achève et la mer commence. Une anthropologie du bout de l'Europe», Terrain 17, pp. 120-134.

Fabian, J. (1983). Time and the Other. How Anthropology Makes Its Object. Nueva York: Columbia University Press.

Gallardo, F. (1995). Antropología. Cruzando a través (desde el otro lado), Santiago de Chile: Fondo Matta.

Goldwater, R. (1986). Primitivism in Modern Art. Cambridge y Londres: Random House.

Jones, J. (1992). «The Colonial Legacy and the Community: The Gallery 33 Project», en: I. Karp, C. M. Kreamer y S. D. Lavine (eds.), Museums and Communities. The Politics of Public Culture. Washington y Londres: Smithsonian Institution, pp. 221241.

Kirshenblatt-Gimblett, B. (1991). «Objects of Ethnography», en: I. Karp y S. D. Lavine (eds), Exhibiting Cultures. The Poetics and Politics of Museum Display. Washington y Londres: Smithsonian Institution, pp. 386-443.

Lestringant, F. (1993). Écrire le monde à la Renaissance. Quinze études sur Rabelais, Postel, Bodin et la littérature géographique, Caen: Paradigme Piblications Universitaires.

Mason, P. (2002). «Faithful to the context? The presentation and representation of American objects in European collections", Anuário Antropológico 98 (Brasilia), pp. 51-95.

- (1995). «Colonialism's Culture and Its Limits». Anthropos 90 (1-3), pp. 576-581.

O'Hanlon, M. (1992). «Unstable images and second skins: artefacts, exegesis and assessments in the New Guinea Highlands», Man 27 (3) pp. 587-608.

Poignant, R. (1992). «Surveying the Field of View: The Making of the RAI Photographic Collection», en: E. Edwards (ed.), Anthropology and Photography 1860-1920, New Haven y Londres: Yale University Press, pp. 42-73.

Pomian, K. (1987). Collectionneurs, amateurs et curieux. Paris, Venise: XVI - XVIII siècle. París: Gallimard.

Price, S. (1989). Primitive Art in Civilized Places, Chicago: The University of Chicago Press.

Price, R. y Price, S. (1992). Equatoria, Londres y Nueva York: Routledge. 
- (1995). «Executing Culture: Musée, Museo, Museum», American Anthropologist 97 (1), pp. 97-109.

Ramada, D. (2007). «Portuguese Navigations. The Pitfalls of National Histories» en J. A. Levenson (ed.), Encompassing the Globe. Portugal and the World in the $16^{\text {th }}$ and $17^{\text {th }}$ Centuries, cat. muestra, Smithsonian Institution, Washington, pp. 37-43.

Rhodes, C. (1994). Primitivism and Modern Art, Londres: Thames and Hudson.

Saporiti, J. y Telles, M. (2014) «Aniceto Rapozo's cabinet at the Lisbon Academy of Sciences. A window into Brazilian eighteenth-century timber resources», Journal of the History of Collections 26 (1), pp. 21-33.

Schnapper, A. (1988). Le géant, la licorne, la tulipe. Collections françaises au XVIIe siècle, París: Flammarion.

Simon, W. J. (1983). Scientific Expeditions in the Portuguese Overseas Territories (1783-1808) and the Role of Lisbon in the Intellectual-Scientific Community of the Late Eighteenth Century, Lisboa.

Spencer, F. (1992). «Some Notes on the Attempt to Apply Photography to Anthropometry during the Second Half of the Nineteenth Century», en: E. Edwards (ed.), Anthropology and Photography 1860-1920, New Haven y Londres: Yale University Press, pp. 99-107.

Stocking Jr. G. W. (1985). «Museums and Material Culture», en Stocking, Jr. (ed.), Objects and Others. Essays on Museums and Material Culture, History of Anthropology, Volume 3, Madison y Londres: The University of Wisconsin Press, pp. 3-14.

Tejera, A. y González, R. (1987). Las culturas aborígenes canarias, Santa Cruz de Tenerife: Interinsular.

Thomas, N. (1991). Entangled Objects: Exchange, Material Culture, and Colonialism in the Pacific. Cambridge: President and Felows of Harvard College.

- (1994). Colonialism's Culture: Anthropology, Travel and Government, Cambridge: Polity Press.

- (1995). Oceanic Art. Londres: Thames and Hudson.

Vogel, S. (1991). «Always True to the Object, in Our Fashion», en: I. Karp y S. D. Lavine (eds), Exhibiting Cultures. The Poetics and Politics of Museum Display. Washington y Londres: Smithsonian Institution, pp. 191-204.

Recibido: 3/03/2013

Aceptado: 15/05/2013 